Article

\title{
Culturally Responsive Teaching in Technology-Supported Learning Environments in Marine Education for Sustainable Development
}

\author{
Ming-Min Cheng ${ }^{1}$, Aurora V. Lacaste ${ }^{2,3}\left(\mathbb{D}\right.$, Cris Saranza ${ }^{2}$ and Hsueh-Hua Chuang ${ }^{1,2, *}$ \\ 1 Institute of Education, National Sun Yat-sen University, 70 Lien-hai Road, Kaohsiung 804, Taiwan; \\ mingmin@g-mail.nsysu.edu.tw \\ 2 International Graduate Program of Education and Human Development, National Sun Yat-sen University, \\ 70 Lien-hai Road, Kaohsiung 804, Taiwan; aurora.lacaste@upou.edu.ph (A.V.L.); \\ saranzacris@gmail.com (C.S.) \\ 3 Faculty of Education, University of the Philippines-Open University, Los Baños 4031, Philippines \\ * Correspondence: hsuehhua@g-mail.nsysu.edu.tw
}

check for updates

Citation: Cheng, M.-M.; Lacaste, A.V.; Saranza, C.; Chuang, H.-H. Culturally Responsive Teaching in Technology-Supported Learning Environments in Marine Education for Sustainable Development. Sustainability 2021, 13, 13922. https:/ / doi.org/10.3390/su132413922

Academic Editor: José Antonio Marín-Marín

Received: 23 November 2021 Accepted: 15 December 2021 Published: 16 December 2021

Publisher's Note: MDPI stays neutral with regard to jurisdictional claims in published maps and institutional affiliations.

Copyright: (C) 2021 by the authors. Licensee MDPI, Basel, Switzerland. This article is an open access article distributed under the terms and conditions of the Creative Commons Attribution (CC BY) license (https:// creativecommons.org/licenses/by/ $4.0 /)$.

\begin{abstract}
This study examined and evaluated how culturally responsive teaching in technologysupported learning environments for preservice teachers was practiced and modeled using experiential learning theory as a guiding framework. Results from qualitative analysis of observational data and outputs of 19 preservice teachers showed that the latter were able to include cultural values and harness technology in their teaching. It was also found that cultural scaffolding enhanced by technology is the most practiced culturally responsive teaching construct during teaching demonstrations. However, technology was used as teachers' instructional tools-in the form of visual aids that illustrate abstract multicultural concepts—instead of students' learning tools. Our findings could be used to develop a K-12 curriculum progression that provides a culturally responsive and contextualized teaching and learning environment for sustainable development.
\end{abstract}

Keywords: culturally responsive teaching; technology-supported learning environment; preservice teacher; experiential learning; professional development

\section{Introduction}

Classrooms have become more diverse than ever, and schools encountering a rapid increase in ethnic and racial diversity are projected to become even more culturally diverse in the future. Culture is defined, in its broadest sense, as the reflection of the way of life of a group of people and as something that is handed down from generation to generation [1]. It is considered as the sum of experiences connected to families' values and traditions [2] and how one is part of a community [3]. Culture thus shapes what we teach, how we teach, and whom we teach. Understanding a student's culture helps teachers evaluate their own teaching methods and become receptive to diverse learning experiences [4], as such playing a crucial role in communicating and receiving information.

Culturally responsive teaching (CRT) is the use of cultural knowledge, past experiences, reference frameworks, and performance styles to increase the efficacy of learning experiences for ethnically diverse learners [5]. Gay [6] (2002) developed a framework grounded in teaching strategies and practices that has five essentials: cultural diversity knowledge, ethnic and cultural diversity curriculum, learning communities, ethnically diverse communication, and culturally diverse instruction. It offers full equitable access to education for students from all cultures [7] and creates an inclusive learning environment in which students feel safe, allowing them to be who they are and feel that their contributions and perspectives are valued and respected [8]. A culturally responsive teacher has the knowledge, attitudes, and skills that give students the ability to understand, communi- 
cate, and work effectively when successfully engaging and teaching students of different cultures [5].

With the rapid growth of advanced educational technologies, features of learning environments have also undergone significant changes [9]. In particular, technologysupported learning environments (TSLEs) are being designed to help learners develop knowledge and skills more efficiently and interactively [10]. The use of information and communications technology (ICT) in teaching favors many teaching- and learning-related processes, with learning outcomes generally connected to creative use of technology in education [11].

Integration of technology into a culturally responsive environment has the capability to create interdependence, social skills, and collaboration among diverse students [12,13], broaden available tools that develop a multicultural pedagogy, and make teachers more inclusive of students' academic needs and varying learning styles [14]. While professional development initiatives have been designed to enhance teachers' CRT and technology integration in terms of professional growth, critical questions remain as to how technology can appropriately be incorporated with CRT use into learning and teaching [15].

In response to the imperative need to integrate CRT pedagogy into technologysupported learning environments, this study designed a teacher preparation course to enhance preservice teachers' awareness with respect to CRT pedagogy, making them able to create and implement CRT and incorporate technology facilities into teaching and learning environments. The teacher preparation course, "Marine Environmental Education", was implemented through a blended cohort following the four stages of experiential learning based on Kolb [16] (1984) to address CRT in TSLE situations in a marine education context. As the preservice teachers had to conduct their teaching demonstrations at a local primary school in the Taijiang area, the curriculum was focused on marine environmental protection in Taijiang National Park in Taiwan.

Taijiang National Park, established in 2009 and located on Taiwan's southwestern coast, covering 39,310 hectares, is the region's eighth national park. It is the only wetland national park in Taiwan and is enriched with natural ecology, human history, and information about the fish and salt industries. Since these characteristics are relevant to the development of marine environmental education, they may also provide students with a view of real-world CRT applications to obtain new insights from their local communities and experiences [17]. It is culturally responsive to consider this park in the Taijiang area, where both teaching and learning should respond to critical concerns of deliberately adjusting and responding to each child's needs while considering their home and community experiences [18].

Furthermore, consistent with the international trend of prioritizing the conservation and preservation of heritage sites, and in response to the 2030 Agenda for Sustainable Development [19], Marine Environmental Education was developed as a preparation course to help preservice teachers address CRT in TSLE in marine education. This qualitative study describes how preservice teachers learned and applied CRT in TSLE through experiential learning and examines the extent to which their experience and knowledge of CRT in TSLE were made evident in their teaching practicum. The following research questions guided the study:

1. How is CRT in TSLE in the Marine Environmental Education program incorporated into the experiential learning of preservice teachers?

2. To what extent do preservice teachers apply CRT in TSLE into their teaching?

\subsection{Related Literature}

\subsubsection{CRT in Technology-Supported Environments (TSLE)}

Culturally responsive teaching is recognized as a pedagogical approach that recognizes the importance of including students' cultural references and experiences in different aspects of learning [5]. Such a consideration of students' cultural backgrounds allows them to make significant connections between what they learn in school and what they experience in real life and in their cultural settings outside school. 
With advances in communication technology and the increasing power of the Internet, as students have more exposure of and interaction with different global and local cultures, it is important that teachers have the necessary attitudes and skills to facilitate learning environments that support and nurture a new generation of culturally diverse students [20]. It is for this reason that CRT readiness must be developed among teachers, especially during their training as preservice teachers.

The rapid growth of educational technologies has significantly changed learning environments. For example, the Internet makes collaborative and inquiry-based activities possible and may even enhance knowledge construction and meaningful learning [21]. The Internet and information technology in themselves have become ubiquitous and influential in the culture and the way of life of a new generation of students. Technology-supported learning environments (TSLE), in particular, have been found to increase learning motivation and student engagement [22,23]. A technology-supported learning environment, or a learning environment infused with the Internet and ICT, can therefore be viewed as both a setting for, and expression of, culturally responsive teaching [24].

Chuang et al. [25] (2020) identified five constructs that constitute culturally responsive teaching in TSLE: cultural values, culturally relevant curricula, cultural scaffolding, multicultural collaboration, and integrating technology and multicultural perspectives. These five constructs were developed mainly from Gay's [6] (2002) CRT categories along with other related studies [26-32]. As a whole, Gay [6] (2002) noted that, in preparing preservice teachers for culturally responsive teaching, it is important to build awareness and knowledge of some essential elements of CRT, particularly developing a knowledge base about cultural diversity, designing culturally relevant curricula, and responding to cultural diversity in the delivery of instruction.

The first construct of CRT in TSLE is cultural value, viz., having a knowledge base about and respect for the student's cultural identity [6,27], including their language, family, community, and culture [25]. The second construct pertains to culturally relevant curricula or integrating local community and activities into TSLE [25] and involves developing meaningful curriculum designs and teaching strategies that link the school to home experiences in an accessible manner using local standard and cultural responses $[6,27,29]$. The third construct is cultural scaffolding, or using the students' own cultures and experiences to expand their learning in a TSLE. It includes teachers' use of technology to communicate with students in all aspects of learning in a way that reflects understanding and care $[6,25,26]$. The fourth construct is multicultural collaboration or providing technology platforms that allow students appropriate interaction [25] to work effectively and collaboratively and build a community of learners that acknowledges diverse perspectives [28,32]. The final construct pertains to integrating technology and multicultural perspectives or incorporating appropriate technologies into teaching and learning activities based on multicultural perspectives $[25,31]$.

Gay [6] (2002) describes culturally responsive teaching as a way to unleash the potential of ethnically diverse students by exploring their academic and psychosocial abilities, implying a need to train preservice teachers about how to teach in a culturally responsive manner. A technology-supported learning environment can potentially help enhance their teaching practices by adding adequate technology experience and competence to fulfill the culturally diverse students' needs [33]; contextualized education for preservice teachers through experiential learning is needed to achieve this goal. Contextualizing learning for preservice teachers will help them to gain increased knowledge about both content and pedagogy and engage them in critical reflection [34].

Following the emergence of the Internet, significant advances in technology-supported learning with respect to the way lessons are presented, how students learn, and how feedback is given to students encouraged the development of online learning environments [35]. Research has also demonstrated how CRT has been incorporated in online learning environments by the recognition of students' and teachers' individualities, languages, and cultures, thus influencing how students study and bring this information to the online 
classroom $[13,36]$. In an online setting, research has shown that most online faculties recognize the need for CRT while also recognizing that their knowledge of CRT may fall short of adequately responding to this need [36]. Meanwhile, Woodley et al. [13] (2017) drew from their experience in online course development, collaborative course design, and innovative classroom practices to describe the four best practices and suggested activities for CRT in online classrooms: validating students' preexisting knowledge, providing comprehensive learning opportunities, transforming student learning with synchronous online meetings, and empowering students through leadership opportunities [13].

In this study, preservice teachers must operationalize CRT during teaching to actual students, which can also be facilitated by matching instructional techniques to students ${ }^{\prime}$ learning styles [6,37]. Overall, preservice teachers can be trained to learn and practice CRT in TSLE by teaching, thus providing them opportunities to develop, critique, and revise lesson plans and instruction delivery to become more culturally fit, especially to the local culture. To prepare teachers in preservice education programs with the knowledge, attitudes, and skills to practice CRT, the current documented project was designed with the five constructs proposed by Chuang et al. [25] (2020) in mind.

\subsubsection{Applying Experiential Learning to Prepare Preservice Teachers for CRT in TSLE}

The experiential learning theory developed by Kolb [16] (1984) is an educational model that defines experiential learning as "the process whereby knowledge is created through the transformation of experience. Knowledge results from the combination of grasping and transforming experience." According to Lee [38] (2019), experiential learning is an important component in teacher education programs, although its implementation varies. It also appears to have the most potential to be of use within an educational setting, particularly in enhancing the teacher-education process [39].

Kolb's experiential learning theory presents a cycle of four elements: concrete experience, reflective observation, abstract conceptualization, and active experimentation. The cycle begins with an experience that the learner (i.e., the preservice teacher) has had, followed by an opportunity to reflect on that experience. Learners may then conceptualize and draw conclusions about what they experienced and observed, leading to future actions in which the learners experiment with different behaviors. Then, the cycle begins anew, as learners have new experiences based on their experimentations [40].

In this paper, we evaluated how preservice teachers designed a mini-lesson and applied CRT in TSLE based on their first-hand experience and in-class participation that applied CRT in TSLE. David Kolb's experiential learning theory (ELT) model served as a guiding framework in practicing and modeling the CRT in TSLE.

\section{Materials and Methods}

\subsection{Participants}

From February to September 2018, a total of 15 preservice teachers from the Marine Environmental Education course offered in a Taiwan teacher education program participated in this study. None of the preservice teachers had received formal training in technology integration in teaching prior to their participation in this course. The participating preservice teachers, from different degree majors, were divided into three groups, and each group was asked, as a course requirement, to design a lesson plan and then demonstrate teaching in a primary school based on their previously designed lesson plans. Table 1 shows an overview of the teaching practicum of each group, including the topic chosen by each group, the background disciplines of the individual members, and the grade level of the classes they taught. Each group was tasked to teach two classes, specifically at 3rd grade and 5 th grade levels. 
Table 1. An overview of preservice teachers' actual practicum.

\begin{tabular}{|c|c|c|c|c|}
\hline Group & Major & Gender & $\begin{array}{l}\text { School Grade of } \\
\text { First Teaching } \\
\text { Practicum }\end{array}$ & $\begin{array}{c}\text { School Grade of } \\
\text { Second Teaching } \\
\text { Practicum }\end{array}$ \\
\hline \multirow{6}{*}{$\begin{array}{l}\text { Fishing farming in } \\
\text { Taijiang }\end{array}$} & $\begin{array}{l}\text { Department of Foreign Language } \\
\text { and Literature }\end{array}$ & Female & \multirow{6}{*}{$\begin{array}{c}5 \text { th } \\
\text { (20 students) }\end{array}$} & \multirow{6}{*}{$\begin{array}{l}5 \text { th } \\
\text { (6 students) }\end{array}$} \\
\hline & Department of Oceanography & Female & & \\
\hline & Department of Marine Environment & Female & & \\
\hline & Department of Chinese Literature & Female & & \\
\hline & Department of Marine & & & \\
\hline & Biotechnology and Resources & Female & & \\
\hline \multirow{6}{*}{ Wetlands' bad luck } & Department of Biological Sciences & Male & \multirow{6}{*}{$\begin{array}{l}5 \text { th } \\
\text { (21 students) }\end{array}$} & \multirow{6}{*}{$\begin{array}{c}\text { 3rd } \\
\text { (19 students) }\end{array}$} \\
\hline & Department of Mechanical & Male & & \\
\hline & Engineering & & & \\
\hline & Department of Electrical & Male & & \\
\hline & Department of Oceanography & Male & & \\
\hline & $\begin{array}{l}\text { Department of Computer Science } \\
\text { and Engineering }\end{array}$ & Female & & \\
\hline \multirow{6}{*}{$\begin{array}{l}\text { Oysters and where to } \\
\text { find them }\end{array}$} & Department of Sociology & Female & \multirow{6}{*}{$\begin{array}{c}\text { 3rd } \\
\text { (21 students) }\end{array}$} & \multirow{6}{*}{$\begin{array}{c}5 \text { th } \\
\text { (20 students) }\end{array}$} \\
\hline & Department of Business & Female & & \\
\hline & Management & & & \\
\hline & $\begin{array}{l}\text { Department of Mechanical } \\
\text { Engineering }\end{array}$ & Male & & \\
\hline & Department of Oceanography & Male & & \\
\hline & $\begin{array}{l}\text { Department of Marine Environment } \\
\text { and Engineering }\end{array}$ & Female & & \\
\hline
\end{tabular}

\subsection{Procedure}

During the Marine Environmental Education teacher preparation course, preservice teachers developed lesson plans in groups based on the concept of CRT in TSLE. To give the preservice teachers an opportunity to design lessons that were culturally relevant to the elementary school students who reside in and are familiar with a given locale, the lesson topics were focused on habitats and marine organisms found at Taijiang National Park. Table 2 shows an overview of each group's lesson plan describing the main topic, objectives, CRT strategies applied, and technology used. Toward the end of the course, the preservice teachers would have actually practiced in elementary schools twice, with a duration of $35 \mathrm{~min}$ for each lesson. Each group was allowed to adjust its lesson plan based on feedback from the first teaching practice. The preservice teachers and students were also informed that the teaching demonstrations were observed and videotaped. The teaching assistants taped the videos under supervision of the classroom teachers. A total of 6 videos, 2 videos for each group, were taken during the practicum. For this study, the videos taken from the teaching practicum of the preservice teachers served as the primary data source; all other collected data were for confirmatory use only. 
Table 2. Lesson plans designed by the preservice teachers.

\begin{tabular}{|c|c|c|c|}
\hline Topic & Content/Objectives & CRT Strategies Applied & Technologies Used \\
\hline $\begin{array}{l}\text { Fish farming in } \\
\text { Taijiang }\end{array}$ & $\begin{array}{l}\text { Understand the conflict of } \\
\text { economics and environment } \\
\text { in fish farming through } \\
\text { introducing fish farming's } \\
\text { present and past. }\end{array}$ & $\begin{array}{l}\text { 1. Makes connections between students' } \\
\text { life experiences and fish farming. } \\
\text { Integrates local community culture } \\
\text { into technology-supported learning } \\
\text { environments: the difference between } \\
\text { past fish farming and modern fish } \\
\text { farming. } \\
\text { 3. Provides opportunities for the } \\
\text { expression of diverse perspectives: } \\
\text { the solution of the fish farming } \\
\text { problem under the conflict of } \\
\text { economics and environment. }\end{array}$ & $\begin{array}{l}\text { 1. Internet: served as a } \\
\text { search engine to find } \\
\text { information that is } \\
\text { related to students' } \\
\text { cultural backgrounds. } \\
\text { 2. } \begin{array}{l}\text { PowerPoint: served as a } \\
\text { visual aid. }\end{array} \\
\text { 3. } \begin{array}{l}\text { Digital video: served as } \\
\text { a visual aid. }\end{array}\end{array}$ \\
\hline
\end{tabular}

1. Introduces the relationship between wetland and humankind, which is contextualized in students' lives and past experiences.

2. Uses appropriate resources to provide the information about the local community surrounding the road development project in Taijiang

Wetlands' the development project of bad luck Taijiang National Park and Jiading Wetland. National Park and Jiading Wetland.

3. Uses cultural scaffolding, i.e., using students' own cultures and experiences related to Taijiang National Park to help students make sense of environmental protection in TSLE.

1. Internet: served as a search engine to find information that is related to students' cultural backgrounds.

2. PowerPoint: served as a visual aid.

3. Digital video: served as a visual aid.
Oysters and where to find them
Learn about environmental pollution through the case of green oysters.
1. Introduces oysters by asking students about related life experiences.

2. Provides culturally relevant examples such as the oyster cuisine that scaffold student learning.

3. Uses appropriate Internet resources to provide cultural information about the local community that used to have an impact on environmental pollution with green oysters.
1. Internet: served as a search engine to find information that is related to students' cultural backgrounds.

2. PowerPoint: served as a visual aid.

3. Kahoot!: served as group activity.

\subsection{Data Collection}

Documentation of the Marine Environmental Education course involved actual classroom observation throughout the course offering, and the content of the lectures and teacher and student activities were recorded. Classroom activities were conducted at different stages, beginning with delivery of lectures on CRT in TSLE and marine environmental topics in the actual practicum. Preservice teachers' class observations were collected to examine how the preservice teachers applied CRT in TSLE through a teaching practicum experience.

\subsection{Data Analysis and Coding Scheme}

Videos from the teaching practicum of each group were collected to examine the extent to which preservice teachers reflected the level of CRT in TSLE while participating in CRT in TSLE in Marine Environmental Education. The coding scheme used to evaluate the teaching practicum was developed in accordance with the five CRT constructs in TSLE [25] and the culturally responsive instruction observation protocol $[41,42]$ (Table 3). 
Table 3. CRT in TSLE coding scheme.

\begin{tabular}{|c|c|}
\hline Construct & Items \\
\hline \multirow{3}{*}{ Cultural values } & 1. The teacher's instruction is contextualized in students' lives, experiences, and individual abilities. \\
\hline & $\begin{array}{l}\text { 2. The teacher demonstrates an ethic of care (e.g., equitable relationships, bonding) in } \\
\text { technology-supported learning environments. }\end{array}$ \\
\hline & $\begin{array}{l}\text { 3. The teacher creates a learning atmosphere that engenders respect for one another and toward } \\
\text { diverse populations. }\end{array}$ \\
\hline \multirow{2}{*}{$\begin{array}{l}\text { Culturally relevant } \\
\text { curricula }\end{array}$} & 4. The teacher integrates local community culture into technology-supported learning environments. \\
\hline & $\begin{array}{l}\text { 5. The teacher uses appropriate Internet resources to provide cultural information about the local } \\
\text { community. }\end{array}$ \\
\hline \multirow{2}{*}{ Cultural scaffolding } & $\begin{array}{l}\text { 6. The teacher uses cultural scaffolding, i.e., using students' own cultures and experiences to help } \\
\text { students make sense of new information in TSLE. }\end{array}$ \\
\hline & 7. The teacher provides culturally relevant examples that scaffold student learning. \\
\hline \multirow{2}{*}{ Multicultural collaboration } & $\begin{array}{l}\text { 8. The teacher engages students to collaborate with others in technology-supported } \\
\text { learning environments. }\end{array}$ \\
\hline & 9. The teachers provide online platforms that allow students to interact with multicultural groups. \\
\hline \multirow{3}{*}{$\begin{array}{l}\text { Integrating technology and } \\
\text { multicultural perspectives }\end{array}$} & $\begin{array}{l}\text { 10. The teacher selects appropriate technology visual aids (e.g., photo, animations, video clips) to } \\
\text { illustrate abstract multicultural concepts. }\end{array}$ \\
\hline & $\begin{array}{l}\text { 11. The teacher uses instructional technology that provides students opportunities for the expression } \\
\text { of diverse perspectives. }\end{array}$ \\
\hline & 12. The teacher provides student opportunities to demonstrate their learning in a variety of ways. \\
\hline
\end{tabular}

There were 6 class videos analyzed in this study, including 2 videos in each group taken from their 2 teaching demonstrations at 3 rd grade and 5th grade levels. Each video ran for at least $35 \mathrm{~min}$, and raters observed and took notes at five-minute intervals for the duration of the class. The raters looked for the teaching strategies and behaviors that could be considered evidence for the presence of each dimension of the five CRT constructs in TSLE using a framework of CRT in TSLE [25]. The CRT in TSLE contains 5 constructs rated on a 4 -point scale $(1=$ Not at all, $2=$ Occasionally, $3=$ Often, $4=$ To a great extent $)$. For example, teaching materials contextualized in students' lives, experiences, etc., would be coded under "Cultural Values," such as "Instructor showed the Cloyster image on the PowerPoint and asks, 'Have you seen Pokémon?" During the class, instructors also frequently utilized local community materials to help students learn new information; this was coded as "Culturally Relevant Curricula. " An example is: "instructor introduced oyster racks with the pictures of local oyster racks in students' living region."

The coding was conducted separately by two raters twice within a month. Each rater was trained to code the videos before coding for the first time. During the rater training, all items in the coding scheme were provided with examples from the videos that would help in assigning codes. Raters were asked to initially code the videos, and the codes they assigned were discussed. To reach a consensus, the coding was revised by each rater based on the common understanding provided by the first coding. The interrater reliability for the raters was found to be Kappa $=0.71(p<0.01)$, showing substantial consistency among raters [43].

\section{Results and Discussion}

\subsection{Experiential Learning and CRT in TSLE}

The preservice education course described in this study demonstrated experiential learning in practice (Figure 1) by allowing the preservice teachers to: (1) experience culturally responsive teaching through engagement in learning activities in a Marine Environmental Education course (concrete experience); (2) reflect on their observations on how CRT is carried out in TSLE (reflective observation); (3) understand what CRT is and 
how technology can be integrated into teaching (abstract conceptualization); (4) design a lesson plan based on reflections and observations (abstract conceptualization); (5) receive feedback from peers and instructors (abstract conceptualization); (6) teach a designated class following the lesson plan made (active experimentation); and (7) refine the lesson plan according to feedback and additional insights gained from actual teaching (active experimentation). The course details, including its stages and the specific activities for each stage, are outlined in Table 4.



Figure 1. The ELT model applied in CRT TSLE.

Table 4. The overview of the CRT in TSLE in Marine Environmental Education curriculum. Course Structure

- $\quad$ Lecture on what CRT is and how to integrate technology into teaching, and introduction on biodiversity and habitats of Taijiang National Park, including the cultures of the communities Concrete Experience within the locale (content/pedagogy).

- Use of Google Sites to share relevant teaching and learning materials (technology).

- $\quad$ Students select a topic related to Taijiang National Park and design a lesson plan based on the constructs of CRT in TSLE (content/pedagogy).

- Groups design lesson plans. Each group selected a topic/issue related to Taijiang National Park and

Reflective Observation designed a lesson plan around it (content/pedagogy).

- $\quad$ Use of Google Sites to share materials and post feedback (technology).

Abstract
Conceptualization

- Refinement of lesson plans based on instructor and peer feedback.

- Micro-teaching (class presentations) to rehearse actual teaching and revision of lesson plan and teaching strategies according to instructor and peers' feedback (reflection).

Active

Experimentation

Practicum consisting of two classroom demonstrations for each group. The preservice teachers made adjustments to the second classroom demonstration based on feedback from the first demonstration (reflection).

\subsection{Extent of CRT in TSLE Application during Practicum}

Table 5 shows the extent to which preservice teachers reflected the level of CRT in TSLE into their practice teaching by participating in CRT in TSLE in Marine Environmental Education. Since the teaching demonstration of each group was video recorded in two actual practicums, there was a combined total of 14 units of analysis per group. Tasks and 
interactions indicating observation or non-observation of the CRT construct items were identified in each analysis unit.

Table 5. Descriptive statistics for the five CRT in TSLE constructs of the class observations.

\begin{tabular}{ccccccc}
\hline \multirow{2}{*}{ CRT in TSLE Constructs } & \multicolumn{2}{c}{$\begin{array}{c}\text { Fish Farming in } \\
\text { TAIJIANG }\end{array}$} & \multicolumn{2}{c}{ Wetlands' Bad Luck } & \multicolumn{2}{c}{$\begin{array}{c}\text { Oysters and Where to } \\
\text { Find Them }\end{array}$} \\
\cline { 2 - 7 } & $\mathbf{M}$ & SD & M & SD & M & SD \\
Cultural values & 1.33 & 0.58 & 1.33 & 0.58 & 1.33 & 0.58 \\
Culturally relevant curricula & 1.00 & 0.71 & 2.00 & 0.00 & 1.00 & 1.50 \\
Cultural scaffolding & 2.50 & 0.00 & 2.00 & 0.00 & 0.00 & 0.71 \\
Multicultural collaboration & 1.00 & 0.00 & 1.00 & 0.00 & 0.71 \\
Integrating technology and & 1.33 & 0.58 & 1.33 & 0.58 & 0.58 \\
multicultural perspectives & & & & & & \\
\hline
\end{tabular}

Note: The five constructs of CRT in TSLE were rated using a 4-point scale $(1=$ Not at all, $2=$ Occasionally, $3=$ Often, $4=$ To a great extent). Total running time of the videos analyzed per group is $70 \mathrm{~min} . \mathrm{M}=$ mean score, $\mathrm{SD}=$ standard deviation (two raters coded the videos independently).

The results showed that cultural scaffolding was the most observed CRT construct during the teaching demonstration. These findings indicate that the preservice teachers provided culturally relevant examples and students' own experiences to help students make sense of new information and scaffold learning of the time. Moreover, integrated technology and online platforms were used mainly for teaching support rather than allowing students to interact and collaborate in multicultural groups. However, teaching demonstrations reflecting the construction of multicultural collaboration were rarely observed. The low adoption of the multicultural collaboration construct may be due to time constraints and the nature of the actual classroom settings.

Analysis of the videos, lecture content, and learning activities revealed three themes that captured how the preservice teachers applied CRT in TSLE through a teaching practicum experience: (1) using culturally relevant and technology-supported instruction commonly occurring in cultural values, and culturally relevant curriculum construction of technology-enhanced cultural scaffolding frequently observed during the scaffolding process; and (2) using technology as a teaching tool, evident both in multicultural collaboration and from integrating technology and multicultural perspectives. Each theme is discussed in further detail below.

\subsubsection{Culturally Relevant and Technology-Supported Instruction}

The preservice teachers were able to include cultural values with technology support in their teaching by contextualizing and considering students' cultural identities as unique individuals that are part of a larger cultural group, such as families and communities. As illustrated below:

The instructor introduced oysters by using familiar character images with students, such as Cloyster, the character in Pokémon.

The instructor showed the Cloyster image on the PowerPoint and asked: "Have you seen Pokémon before? We are going to introduce something similar to this."

Students: "Yes. This is called Cloyster."

However, only to a lesser extent was creating a learning atmosphere that engendered mutual respect of culture and demonstrated an ethic of care observed; this was probably due to the short time that the preservice teachers spent with the students. Powell et al. [41] (2016) added that, even though teachers may have cared about the students and wanted to have a positive relationship, they might not have known how to show that care, particularly for multicultural background students. 
Likewise, the integration of the local community culture presented in photos and video clips was evident during the discussion, mostly as examples situated in the locale itself. One example is illustrated in the video:

Instructor: "The fish is too cheap now, so the fisherman has to raise a lot of fish to minimize their losses. What can be done to resolve this problem?"

Student: "They can increase the price of fish?"

Instructor: "Fishermen from Taijiang practice canning of fish and turn them into cultural and creative goods in order to raise the price."

Previous research has found that preservice teachers who have developed positive attitudes toward technology integration [44] commonly use basic technology skills in creating teaching-related materials such as lesson plans and lecture presentations during their teacher preparation program $[45,46]$. This finding is consistent with the results of this study noting that the groups introduced and familiarized students with locally available oysters in Taijiang, or with a previous electronic waste pollution crisis at a local wetland, showing them using pictures and other visual materials. Moreover, the groups' use of appropriate Internet resources to provide information about the local culture reflected their application of culturally relevant curricula within TSLE to their teaching.

\subsubsection{Technology-Enhanced Cultural Scaffolding}

While cultural scaffolding enhanced by technology is the most practiced CRT construct during teaching demonstrations, the preservice teachers only used basic technology (e.g., photos, animations, and PowerPoint presentations) to support and develop scaffolding interactions. They found it easy to use PowerPoint with animations and photos in modeling, prompting sharing of knowledge and tips about their local community and its multicultural perspective. Most groups were able to introduce a topic by systematically asking questions flashed in PowerPoint presentations that touched on students' experiences and knowledge while gradually linking their answers to the topic to be learned. Questions were usually directed toward confirmation of their prior knowledge or experiences. Examples are: "Have you been to Qigu Yanshan?" and "Have you eaten oysters?" from the fish farm and wetlands groups. The groups also gave culturally relevant examples to broaden and enhance the students' understanding of the topics, e.g., "Simu fish is one of the fishes we eat very often." However, in general, asking scaffolding questions was usually limited to the first part of the class, often used to introduce a topic, and there were no follow-ups or links to the subsequent activities and lectures. Moreover, the technology used primarily served as a visual aid to show culturally relevant examples and as a prompt during the scaffolding process. This could also be attributed to the limited time available for preservice teachers to explore other technology given the risks of technical troubles that might disrupt their teaching in class, or the likelihood that the technology might require them to face a steep learning curve. However, James et al. [47] (2020) suggested that technologies deliver maximum value when fully integrated into the learning experience, such as scaffolding in reflective writing activities, peer feedback, and gamification to motivate action-based participation.

While students can benefit from technology-enhanced scaffolds because they can communicate various processes and cognitive tasks while still allowing the teacher to concentrate on complex, personalized scaffolding [48], teachers are most likely to use technology-enhanced scaffolds to complement existing teaching methods rather than contextualizing and incorporating the scaffolds to help students develop problem-solving skills [49]. Furthermore, scaffolding in the classroom is often compromised by students inadequate prior knowledge and experience as well as teachers' disposition to lecture rather than facilitate inquiry [50]. Preservice teachers should take introductory technical skills classes to develop their proficiency because it is predictive of how they might use technology in their classrooms [51]. 


\subsubsection{Technology Used as a Teaching Tool}

While the preservice teachers integrated the use of technology into most of their classes, they mainly utilized these technologies as teaching tools that serve as visual aids to illustrate abstract multicultural concepts. They seldom used them as learning tools for demonstrating their learning and expressing their diverse perspectives. This is possibly because preservice teachers primarily think about using the technology to teach; they need more hands-on experience or modeling so they can discover how technology can also serve as a learning tool. This supports previous research that suggests that even though new teachers use technology, they often do so at only a very basic level, failing to optimize a technology's capacity to enhance learning and foster desired 21st century skills such as critical thinking and problem solving [52,53].

This concern possibly explains why, in all groups, there was less integration of online platforms that allowed students to interact with multicultural groups. Only the oyster group, to a lesser extent, applied multicultural collaboration by engaging the students to collaborate with others through group competitions in TSLE. In most groups, students demonstrated their learning orally (e.g., sharing activities, presenting on stage) and through writing (e.g., worksheets), but with less integration of technologies in expressing diverse perspectives. This concurs with the idea that when students from diverse cultures interact, collaborative learning may be difficult; one of the most effective ways to educate people about collaborating when connecting multicultural groups worldwide is through the use of technological tools [54].

Technology is a driving principle underlying the significant priorities of intercultural education and collaboration for the 21st century. Its implementation in the learning environment has inferences for the teacher, for learner characteristics, and for teachinglearning styles, which are all strongly interdependent [55]. Furthermore, its effectiveness is achieved when students use technology to obtain timely information, to analyze and synthesize, to express their perspectives, and to make professional presentations; this is why it should become just as accessible as other classroom tools [56]. Teachers in culturally diverse classrooms must be mindful that students with different cultural backgrounds may have different needs [57], and they should know how to use specific teaching techniques and technological tools to create a positive learning environment that addresses such needs [58]. This is why teachers' lack of culturally diverse classroom experience limits the implementation and efficiency of collaborative learning strategies [59].

This study's framework is anchored in the premise that if CRT in TSLE is reflected in the teaching and learning process, it may help develop and improve CRT curricula and teaching practices in TSLE and enhance academic rigor for diverse students.

Overall, the minimal extent of application of CRT in TSLE during the practicum may be due to the limited time to deliver the course and interact with students. There were only two opportunities to teach the students; hence, there was not enough time to fully implement CRT in TSLE in the classroom. The preservice teachers were not acquainted with the students or school before giving their lessons, and their background knowledge of the class and the existing technology available for their use was limited. However, experiencing CRT in TSLE in the classroom is an important first step in helping preservice teachers gain perspectives on how CRT is practiced in the classroom so as to utilize technology as a teaching and learning tool.

\section{Conclusions}

This study focused on determining which elements of CRT in TSLE were applied during the active experimentation part of experiential learning. Overall, the preservice teachers were able to use all five constructs that characterize CRT in TSLE, despite applying it only to a minimal extent, with cultural scaffolding as the most utilized construct. The findings support Kolb's [16] (1984) assertion that knowledge about the concept-in this case, CRT in TSLE-resulted from the preservice teachers' own experiences in a CRT in TSLE classroom that has been grasped and transformed according to how they understood 
it. It is understandable that, because of time constraints and a lack of prior connection with the particular pupils in their class, the preservice teachers were not able to readily apply or demonstrate the knowledge they acquired during the practicum.

The study shows the importance of intentionally designing activities and building a class schedule that will provide enough time and concrete experience for preservice teachers to reflect upon CRT in TSLE, as well as to implement reflections and conclusions drawn from the experience itself. It is also important to provide preservice teachers with background information about the school and the students they will be teaching, including the technology infrastructure of the school and student demographics.

To effectively operationalize core concepts during instruction, educators must fully understand the process and the context through which experiential learning occurs [60]. In training the preservice teachers for culturally responsive instruction in technologysupported environments, therefore, experience alone would not be enough. Reflecting on an experience, making generalizations about the experience, and testing the experienceprocesses that require time and careful curriculum planning-must be given emphasis to optimize the potential value of an instructional approach that is experiential in nature.

Results from the study have implications for how experiential learning might be applied to promote CRT in TSLE in teacher education programs. First, they shed light on teacher education programs' commitment to holistically educating future teachers by encouraging preservice teachers to reflect on their firsthand experience. For an implementation of a similar course in the future, an additional round of peer feedback and review could be performed to help groups reflect on how to make lessons even more culturally responsive and aligned with the expectations of the practicum. For example, the feedback could be more centered around the five concepts of CRT in TSLE. Having feedback from peers, teacher educators, and the teacher with experiences in CRT, offering a chance to make revisions before the actual classroom teaching, may improve the extent to which the preservice teachers incorporate CRT in TSLE. In addition, during the active experimentation stage, preservice teachers could be given more opportunities to reflect more deeply on their teaching practicum based on the items of CRT in TSLE to scaffold their acknowledgement of CRT.

Second, these results necessitate attempts to reconsider the core curriculum in adapting CRT, emphasizing reforming teachers' pedagogical practices and classroom management. Third, this research can inspire preservice teachers to reflect on their values and how they fit with their professional ones, thus linking them to students and communities. Fourth, this study will assist teacher educators in evaluating their existing instructional practices and reflecting on how the curriculum and learning environments represent students' lives, cultures, and experiences. Because there often appears to be a misalignment between classroom practice and methodologies required for realistic and successful culturally responsive pedagogy, preservice teachers "should adopt the idea of critical multiculturalism and start with self-reflection and evaluation" [61]. Finally, this study offers insights for both preservice and in-service teachers on how inclusivity and cultural responsiveness, a goal for education captured in Sustainable Education Goal 4 [19], can be actively applied and refined in classroom settings. Experiential learning of culturally responsive teaching can promote reflective practices among teachers, leading them to a personal commitment to provide inclusive and equitable quality education, as well as a nurturing learning environment to maximize their students' capabilities.

There are some limitations that must be noted in terms of the generalization of this study. As the population of this study examined three groups of preservice teachers in one school, transferability of the results to theoretical propositions and other preservice teacher populations is limited. To understand the extent of the application of CRT in TSLE from the point of view of preservice teachers, we suggest that, in future studies, the rubric for CRT in TSLE should be used to evaluate written lesson plans and actual teaching demonstrations. Moreover, in forming the preservice groups, gender identity was not considered. It is recommended that gender identity should be factored in to 
examine the influence of gender on CRT teaching design and practices. Furthermore, since the population in this study consisted entirely of preservice teachers enrolled in the Marine Environmental Education course, and the topics of the lesson were decided by the participants, opportunities for future research could include similar studies from the perspectives of preservice teachers on other topics, fields, and in-service teachers in secondary and tertiary education. In addition, a longitudinal study is also recommended to gain a clearer understanding of the extent of CRT in TSLE applications.

Finally, the findings of this study, when integrated with those of other studies on culturally responsive and technology-supported education, could be used to develop a K-12 curriculum progression that provides culturally responsive and contextualized teaching and learning environments for sustainable development. CRT in TSLE has the potential to improve the number of students who feel a sense of racial and ethnic pride and belonging linked to school engagement [62], learning interest [63], as well as academic performance [64], and to motivate teachers to action by adopting teaching strategies aimed at creating inclusive and culturally responsive classrooms [65].

Author Contributions: Conceptualization, H.-H.C.; Methodology, H.-H.C., M.-M.C., and A.V.L.; Analysis, H.-H.C., M.-M.C., and A.V.L.; Writing-Original Draft Preparation, M.-M.C., A.V.L., and C.S.; Writing - Review and Editing, H.-H.C.; Supervision, H.-H.C. All authors have read and agreed to the published version of the manuscript.

Funding: This research project was supported in part by the Ministry of Science and Technology, Taiwan; No. MOST 106-2511-S-110-003-MY2.

Institutional Review Board Statement: The study was conducted according to the guidelines of the Declaration of Helsinki, and approved by the National Cheng Kung University Human Research Ethics Committee (protocol code NCKU HREC-E-106-114-2 and 9 September 2017).

Informed Consent Statement: Informed consent was obtained from all subjects involved in the study.

Conflicts of Interest: The authors declare no conflict of interest.

\section{References}

1. Matsumoto, D.; Kudoh, T.; Takeuchi, S. Changing Patterns of Individualism and Collectivism in the United States and Japan. Cult. Psychol. 1996, 2, 77-107. [CrossRef]

2. Albert, I.; Trommsdorff, G. The Role of Culture in Social Development Over the Lifespan: An Interpersonal Relations Approach. Online Read. Psychol. Cult. 2014, 6, 1. [CrossRef]

3. Stroope, S. Education and religion: Individual, congregational, and cross-level interaction effects on biblical literalism. Soc. Sci. Res. 2011, 40, 1478-1493. [CrossRef]

4. Mantiri, O. The Influence of Culture on Learning Styles. Asia-Pacific International University. Saraburi. 2013. Available online: https://ssrn.com/abstract=2566117 (accessed on 8 November 2021). [CrossRef]

5. Gay, G. Culturally Responsive Teaching: Theory, Research, and Practice; Teachers College Press: New York, NY, USA, 2018.

6. Gay, G. Preparing for Culturally Responsive Teaching. J. Teach. Educ. 2002, 53, 106-116. [CrossRef]

7. Samuels, A.J. Exploring Culturally Responsive Pedagogy: Teachers' Perspectives on Fostering Equitable and Inclusive Classrooms. SRATE J. 2018, 27, 22-30.

8. Suárez-Orozco, C.; Strom, A.; Larios, R.A. Culturally Responsive Guide to Fostering the Inclusion of Immigrant-Origin Students. Available online: https://reimaginingmigration.org/wp-content/uploads/2018/07/Final_Inclusive_CS0-Curriculum_V7_8_9 2018-4.pdf (accessed on 1 November 2021).

9. Price, J.K. Transforming learning for the smart learning environment: Lessons learned from the Intel education initiatives. Smart Learn. Environ. 2015, 2, 16. [CrossRef]

10. Alkhabra, S.; Abdullah, N. Impact of Technology from Learning Environment to Organizational Practices. Int. J. Soc. Sci. Manag. 2016, 3, 108-114. [CrossRef]

11. Sangrà, A.; González-Sanmamed, M. The role of information and communication technologies in improving teaching and learning processes in primary and secondary schools. Australas. J. Educ. Technol. 2010, 26, 207-220. [CrossRef]

12. Frederick, R.; Donnor, J.K.; Hatley, L. Culturally responsive applications of computer technologies in education: Examples of best practice. Educ. Technol. 2009, 49, 9-13.

13. Woodley, X.; Hernandez, C.; Parra, J.; Negash, B. Celebrating Difference: Best Practices in Culturally Responsive Teaching Online. TechTrends 2017, 61, 470-478. [CrossRef]

14. Morgan, K. Technology Integration in Multicultural Settings. In Handbook of Research on Educational Communications and Technology; Springer: Singapore, 2014; pp. 867-871. 
15. Chuang, H.-H. Leveraging CRT awareness in creating web-based projects through use of online collaborative learning for pre-service teachers. Educ. Technol. Res. Dev. 2016, 64, 857-876. [CrossRef]

16. Kolb, D.A. Experiential Learning: Experience as the Source of Learning and Development; FT Press: Upper Saddle River, NJ, USA, 2014.

17. Chou, P.-I.; Su, M.-H.; Wang, Y.-T. Transforming teacher preparation for culturally responsive teaching in Taiwan. Teach. Teach. Educ. 2018, 75, 116-127. [CrossRef]

18. Price, C.L.; Steed, E.A. Culturally responsive strategies to support young children with challenging behavior. YC Young Child. 2016, 71, 36-43.

19. Department of Economic and Social Affairs. Transforming Our World: The 2030 Agenda for Sustainable Development. Available online: https:/ / sdgs.un.org/2030agenda (accessed on 8 November 2021).

20. Moore, K.D.; Jacqueline, H. Effective Strategies for Teaching in K-8 Classrooms; Sage: Thousand Oaks, CA, USA, 2011.

21. Lee, M.-H.; Tsai, C.-C. Exploring teachers' perceived self efficacy and technological pedagogical content knowledge with respect to educational use of the World Wide Web. Instr. Sci. 2008, 38, 1-21. [CrossRef]

22. Chuang, Y.-T. Increasing Learning Motivation and Student Engagement through the Technology- Supported Learning Environment. Creative Educ. 2014, 5, 1969-1978. [CrossRef]

23. Leese, M. Out of class-out of mind? The use of a virtual learning environment to encourage student engagement in out of class activities. Br. J. Educ. Technol. 2009, 40, 70-77. [CrossRef]

24. Rao, K. Universal design for learning and multimedia technology: Supporting culturally and linguistically diverse students. $J$. Educ. Multimed. Hypermedia 2015, 24, 121-137.

25. Chuang, H.-H.; Shih, C.-L.; Cheng, M.-M. Teachers' perceptions of culturally responsive teaching in technology-supported learning environments. Br. J. Educ. Technology 2020, 6, 2442-2460. [CrossRef]

26. Bennett, S.; Lockyer, L.; Agostinho, S. Towards sustainable technology-enhanced innovation in higher education: Advancing learning design by understanding and supporting teacher design practice. Br. J. Educ. Technol. 2018, 49, 1014-1026. [CrossRef]

27. Boon, H.; Lewthwaite, B. Development of an instrument to measure a facet of quality teaching: Culturally responsive pedagogy. Int. J. Educ. Res. 2015, 72, 38-58. [CrossRef]

28. Brown, J.C.; Crippen, K.J. The Knowledge and Practices of High School Science Teachers in Pursuit of Cultural Responsiveness. Sci. Educ. 2016, 101, 99-133. [CrossRef]

29. Liu, Y.-C.; Huang, T.-H. Science Education Curriculum Development Principles in Taiwan: Connecting with Aboriginal Learning and Culture. Eurasia J. Math. Sci. Technol. Educ. 2016, 13, 1341-1360. [CrossRef]

30. Koh, J.H.L.; Chai, C.S.; Tsai, C.-C. Examining practicing teachers' perceptions of technological pedagogical content knowledge (TPACK) pathways: A structural equation modeling approach. Instr. Sci. 2013, 41, 793-809. [CrossRef]

31. Nikolić, V.; Petković, D.; Denić, N.; Milovančević, M.; Gavrilović, S. Appraisal and review of e-learning and ICT systems in teaching process. Phys. A Stat. Mech. Its Appl. 2019, 513, 456-464. [CrossRef]

32. Popov, V.; Noroozi, O.; Barrett, J.B.; Biemans, H.J.; Teasley, S.D.; Slof, B.; Mulder, M. Perceptions and experiences of, and outcomes for, university students in culturally diversified dyads in a computer-supported collaborative learning environment. Comput. Hum. Behav. 2014, 32, 186-200. [CrossRef]

33. Darling-Aduana, J.; Heinrich, C.J. The role of teacher capacity and instructional practice in the integration of educational technology for emergent bilingual students. Comput. Educ. 2018, 126, 417-432. [CrossRef]

34. Edwards, S.; Kuhlman, W. Culturally responsive teaching: Do we walk our talk? Multicult. Educ. 2007, $14,45$.

35. Cook, C.W.; Sonnenberg, C. Technology And Online Education: Models For Change. Contemp. Issues Educ. Res. (CIER) 2014, 7, 171-188. [CrossRef]

36. Heitner, K.L.; Jennings, M. Culturally Responsive Teaching Knowledge and Practices of Online Faculty. Online Learn. 2016, 20, 54-78. [CrossRef]

37. Soylu, A.; Kaysıll, A.; Sever, M. Refugee Children and Adaptation to School: An Analysis through Cultural Responsivities of the Teachers. Egitim ve Bilim 2020, 45, 313-334. [CrossRef]

38. Lee, J.F.K. Enhancing preservice teachers' professional competence through experiential learning. J. Educ. Teach. 2019, 45, 353-357. [CrossRef]

39. Clark, R.W.; Threeton, M.D.; Ewing, J.C. The Potential of Experiential Learning Models and Practices In Career and Technical Education \& Career and Technical Teacher Education. J. Career Tech. Educ. 2010, 25, 46-62. [CrossRef]

40. Oxendine, C.; Robinson, J.; Willson, G. "Experiential learning." Emerging perspectives on learning, teaching and technology. Athens, GA: Department of Educational Psychology and Instructional Technology, University of Georgia. 2004. Available online: http: / / epltt.coe.uga.edu/index.php (accessed on 8 November 2021).

41. Powell, R.; Cantrell, S.C.; Malo-Juvera, V.; Correll, P. Operationalizing culturally responsive instruction: Preliminary findings of CRIOP research. Teach. Coll. Rec. 2016, 118, 1-46. [CrossRef]

42. Civitillo, S.; Juang, L.P.; Badra, M.; Schachner, M.K. The interplay between culturally responsive teaching, cultural diversity beliefs, and self-reflection: A multiple case study. Teach. Teach. Educ. 2019, 77, 341-351. [CrossRef]

43. Landis, J.R.; Koch, G.G. The Measurement of Observer Agreement for Categorical Data. Biometrics 1977, 33, 159-174. [CrossRef]

44. Akturk, A.O.; Izci, K.; Caliskan, G.; Sahin, I. Analyzing preservice teachers' attitudes towards technology. Online Submiss. 2015, 9, 3960-3966. 
45. Cohen, E.; Hoz, R.; Kaplan, H. The practicum in preservice teacher education: A review of empirical studies. Teach. Educ. 2013, 24, 345-380. [CrossRef]

46. Saini, C.; Abraham, J. Implementing Facebook-based instructional approach in pre-service teacher education: An empirical investigation. Comput. Educ. 2019, 128, 243-255. [CrossRef]

47. James, N.; Humez, A.; Laufenberg, P. Using Technology to Structure and Scaffold Real World Experiential Learning in Distance Education. TechTrends 2020, 64, 636-645. [CrossRef]

48. Sharma, P.; Hannafin, M.J. Scaffolding in technology-enhanced learning environments. Interact. Learn. Environ. 2007, 15, 27-46. [CrossRef]

49. Cuban, L.; Kirkpatrick, H.; Peck, C. High Access and Low Use of Technologies in High School Classrooms: Explaining an Apparent Paradox. Am. Educ. Res. J. 2001, 38, 813-834. [CrossRef]

50. Kim, M.C.; Hannafin, M.J. Scaffolding problem solving in technology-enhanced learning environments (TELEs): Bridging research and theory with practice. Comput. Educ. 2011, 56, 403-417. [CrossRef]

51. Giles, R.M.; Kent, A.M. An Investigation of Preservice Teachers' Self-Efficacy for Teaching with Technology. Asian Educ. Stud. 2016, 1, 32. [CrossRef]

52. Batane, T.; Ngwako, A. Technology use by pre-service teachers during teaching practice: Are new teachers embracing technology right away in their first teaching experience? Australas. J. Educ. Technol. 2016, 33, 48-61. [CrossRef]

53. DeSantis, J.D.; Rotigel, J.V. Evolving a technology integration ethos: Technology habits of preservice and in-service teachers. J. Instr. Pedagog. 2014, 14, 1-12.

54. Cagiltay, K.; Bichelmeyer, B.; Akilli, G.K. Working with multicultural virtual teams: Critical factors for facilitation, satisfaction and success. Smart Learn. Environ. 2015, 2, 11. [CrossRef]

55. Müller, F.A.; Wulf, T. Technology-supported management education: A systematic review of antecedents of learning effectiveness Int. J. Educ. Technol. High. Educ. 2020, 17, 1-33. [CrossRef]

56. Keengwe, J.; Onchwari, G. (Eds.) Handbook of Research on Literacy and Digital Technology Integration in Teacher Education; IGI Global: Hershey, PA, USA, 2019.

57. Brok, P.D.; van Eerde, D.; Hajer, M. Classroom interaction studies as a source for teacher competencies: The use of case studies with multiple instruments for studying teacher competencies in multicultural classes. Teach. Teach. 2010, 16, 717-733. [CrossRef]

58. Wubbels, T.; Brok, P.D.; Veldman, I.; Van Tartwijk, J. Teacher interpersonal competence for Dutch secondary multicultural classrooms. Teach. Teach. 2006, 12, 407-433. [CrossRef]

59. Tielman, K.; Brok, P.D.; Bolhuis, S.; Vallejo, B. Collaborative learning in multicultural classrooms: A case study of Dutch senior secondary vocational education. J. Vocat. Educ. Train. 2011, 64, 103-118. [CrossRef]

60. Baker, M.; Robinson, S.; Kolb, D. Aligning Kolb's Experiential Learning Theory with a Comprehensive Agricultural Education Model. J. Agric. Educ. 2012, 53, 1-16. [CrossRef]

61. Ebersole, M.; Kanahele-Mossman, H.; Kawakami, A. Culturally Responsive Teaching: Examining Teachers' Understandings and Perspectives. J. Educ. Train. Stud. 2015, 4, 97-104. [CrossRef]

62. Morris, K.; Seaton, E.; Iida, M.; Johnson, S.L. Racial Discrimination Stress, School Belonging, and School Racial Composition on Academic Attitudes and Beliefs among Black Youth. Soc. Sci. 2020, 9, 191. [CrossRef]

63. Borrero, N.E.; Yeh, C.J. The Multidimensionality of Ethnic Identity Among Urban High School Youth. Identity Int. J. Theory Res. 2011, 11, 114-135. [CrossRef]

64. Dee, T.S.; Penner, E.K. The Causal Effects of Cultural Relevance. Am. Educ. Res. J. 2017, 54, 127-166. [CrossRef]

65. O'Leary, E.S.; Shapiro, C.; Toma, S.; Sayson, H.W.; Levis-Fitzgerald, M.; Johnson, T.; Sork, V.L. Creating inclusive classrooms by engaging STEM faculty in culturally responsive teaching workshops. Int. J. STEM Educ. 2020, 7, 1-15. [CrossRef] [PubMed] 